\title{
PATRIMÔNIO E PAISAGEM CULTURAL: CONTRIBUIÇÕES PARA INTERVENÇÕES PLANEJADAS NA BAĊIA HIDROGRÁFICA DO AGUAPEÍ / SP.
}

\section{Maria Alice Gaiotto ${ }^{1}$}

RESUMO: As abordagens teórico-conceituais transdisciplinares, aqui, dos (re) desenhos de localidades paulistas, há que considerarem os impactos sócio-econômicos, culturais e ambientais, integrados à memória e identidade das comunidades, para garantir o repensar do ensino e pesquisas futuras da Arquitetura e Urbanismo. A partir de 1970, marco do desenvolvimento rumo ao interior de São Paulo, visivelmente identificam-se os elementos ordenadores do perfil da paisagem, e da degradação dos recursos naturais, também, no território entre os rios do Peixe e Aguapeí, até a foz desses, com o rio Paraná. Nessa porção da Alta Paulista, a Oeste-Noroeste do Estado, delimita-se o objeto em estudo, onde também se localiza Marília, uma das cidades médias paulistas, polarizando outras, menores. Em tese, sob o prisma da metodologia participativa; reconhecido e resgatado; valorizado, preservado e conservado para as gerações futuras; o Patrimônio Cultural, como ordenador da Paisagem, pode colaborar no planejamento e qualidade dos espaços, muitas vezes, subutilizados e/ou degradados, visando qualidade de vida e inclusão social.

Palavras-Chaves: Patrimônio e Paisagem Cultural; Interior Paulista; Bacia Hidrográfica do Aguapeí.

\footnotetext{
${ }^{1}$ Arquiteta e Urbanista. Doutora em Estruturas Ambientais Urbanas pela FAU-USP. Professora do Curso de Arquitetura e Urbanismo - Faculdades Faccat - Tupã/SP.

E-mail: maria_alicegaiotto@yahoo.com.br
} 


\section{INTRODUÇÃO}

Ao representar o máximo grau na integração do conhecimento, tanto por assimilação, como por reflexão da cultura enquanto referencial da existência humana; em busca da sustentabilidade social, a transdisciplinaridade (que está entre as disciplinas, através dos diferentes conteúdos e, ao mesmo tempo, além de todas elas) remete a uma nova atitude diante do mundo, possibilitando a idéia de transcendência, na compreensão da complexidade (Morin, 2003).

Por isso, no reconhecimento do contexto transdisciplinar para o desenvolvimento de pesquisas ligadas a Arquitetura e Urbanismo, o recorte desta proposta justifica-se devido o interesse na continuidade das investigações e considerações declinadas por GAIOTTO (2002), em sua tese de doutorado, relacionada ao território de uma bacia hidrográfica.

Tal e qual, sob o prisma do planejamento ambiental dos (re) desenhos urbanos, fundamentais ao desenvolvimento mais sustentável do interior paulista; para a escolha dos fatores preponderantes e seus limites, opta-se pelo estudo da porção de território localizado na região da Alta Paulista, entre os rios do Peixe e Aguapeí.

$\mathrm{Na}$ busca de proposições objetivas, para o planejamento da ocupação futura de localidades, inseridas em bacia hidrográfica, há que se considerarem os seus patrimônios e paisagens culturais, sem esquecer a complexidade da visão sistêmica de investigações dessa natureza. Assim, ancorada em MORIN (2003), interessa a definição de "pensamento complexo" porque apresenta uma nova forma de abordagem da totalidade, ou seja, uma visão de complementaridade entre a concepção linear e a sistêmica das diferentes intervenções humanas da realidade, da qual, cada ser possui a sua própria visão e interpretação.

O certo, ou o errado, para um, não seria o mesmo para o outro, e assim, sucessivamente. Portanto, na visão sistêmica avaliam-se os processos de construção da realidade, tanto do ponto de vista econômico, como social, cultural e ambiental, no sentido de lançar, em busca de soluções viáveis à manutenção das gerações presentes e futuras, tão preconizadas nos pressupostos do desenvolvimento mais sustentável. 
E, como exemplo, cita-se ARGOLLO FERRÃO (2004) e suas pesquisas sobre a arquitetura rural paulista, nas quais defende as teorias do "pensamento complexo" e o caráter transdisciplinar desses conteúdos; demonstrando que "a complexidade, longe de ser um conceito apenas teórico, é uma característica do mundo contemporâneo que se torna explícita toda vez que se colocam questões sobre relações intrincadas como as que se dão no âmbito do sistema cidade-campo". Tanto que, nesse contexto, para esse autor, a relação entre a evolução das propriedades rurais e a ordenação da paisagem visualiza os processos inerentes à implantação física do patrimônio edificado de interesse históricoarquitetônico relacionados à co-evolução da paisagem cultural.

As propriedades agrícolas devem ser caracterizadas como espaços produtivos inseridos no contexto de um complexo agro-industrial-comercial, e, portanto, entendidas como unidades pertencentes a uma cadeia específica. As relações entre arquitetura e técnicas de produção têm origem na própria formação deste espaço, que, visto como um sistema possui variáveis específicas a cada região e período histórico (Argollo Ferrão, 2003).

O uso e a ocupação dos solos da bacia hidrográfica, também, determinam a correlação da dinâmica sócio-econômica, cultural e ambiental, na utilização dos recursos naturais, principalmente os hídricos. Situação que tem demonstrado a notória diversificação das áreas rurais do interior paulista, tanto que, ali, não se restringem à agropecuária e agroindústria. Incorporam atividades outras, consideradas não agrícolas, tais como de prestação de serviços pessoais; indústrias de transformação e da construção civil; comércio em geral; serviços sociais e culturais; condomínios e chácaras de recreio, entre outros usos de características urbanizadas (Gaiotto, 2002).

Além disso, para SANTORO et. al. (2004) essas novas oportunidades de trabalho e renda acabam por constituir um "novo rural", que incorporam atividades diversas, valorizando, ainda mais, o mercado imobiliário dos solos rurais paulistas, onde, além da importância econômica, se amplia o sócio-cultural. Situações favoráveis ao repensar de políticas públicas com base nessa nova realidade.

Esse desenvolvimento, que também propicia intensa expansão urbana, gera franjas periféricas aos antigos centros; inclusive, em forma bolsões de miséria ou de condomínios fechados e chácaras de recreio de alto padrão. A partir de 1970, com a descentralização industrial da Grande São Paulo, rumo ao interior; destacam-se os mais sérios problemas 
ambientais, principalmente os de natureza orgânica e inorgânica, que pressionam os recursos hídricos, insustentáveis para a qualidade de vida do lugar (Gaiotto, 2002).

Em tese, esse seria mais um fenômeno calcado no desenvolvimento econômico, visivelmente, encontrado nas diferentes regiões hidrográficas e cidades médias do interior paulista. Tanto que, para SPÓSITO (2007):

Até os anos de 1970 e 1980, a circulação intra-urbana nessas cidades articulava-se em torno de um centro principal, compondo estruturas monocêntricas fortemente integradas a uma única área importante de concentração de estabelecimentos comerciais e de serviços. Nos últimos vinte anos, observou-se multiplicação de áreas de concentração dessas atividades (eixos comerciais, centros comerciais em bairros de bom poder aquisitivo e shopping centers), bem como verificou-se o fenômeno de diversificação delas, acompanhado de segmentação dos mercados consumidores, segundo diferentes padrões de consumo e maior ou menor facilidade para se locomover por automóvel.

Para a finalidade desta pesquisa, na região entre os rios do Peixe e Aguapeí, merece destaque, Marília, cidade de médio porte que parece integrar mais uma importante e planejada rede de núcleos urbanos, cuja dinâmica de crescimento (sustentável ou não?...) tem levado ao desenvolvimento local e regional, visando o bem estar das gerações presentes e futuras.

Ainda existem perguntas, que não querem calar:-

i. Ao se considerar a bacia hidrográfica como objeto da análise da ocupação do território rural pode-se relacioná-lo ao urbano, adotando o mesmo paradigma utilizado na elaboração dos atuais Planos Diretores das cidades médias do interior paulista?

ii. E o que dizer de Marília: o seu atual Plano Diretor evidencia-se os devidos instrumentos norteadores das intervenções e desenhos urbanos?

iii. Qual a influência das demais cidades menores, que compõem essa região, entre rios (do Peixe e Aguapeí), para as prováveis intervenções planejadas e novos desenhos urbanos?

$\mathrm{Na}$ análise da dinâmica urbana, são tantos os fatores de influencia:

A influência social, cultural e econômica reflete-se na organização do espaço urbano, e, em razão desses reflexos dominantes, reproduzem-se, até com certo sucesso, os elementos presentes nas paisagens dos centros com maior influencia. Assim, as imagens formais das grandes cidades são claramente representadas de um modo especifico na paisagem urbana das cidades médias (...). Essas cidades incorporam valores que sintetizam padrões qualitativos da cidade brasileira, e nelas elementos e estruturas dos grandes centros estão presentes, ainda que organizados de uma maneira mais simples e com um porte menor (Landim, 2004: 16). 
Esses, entre outros fatores, embasam esta proposição, que se encontra ancorada nas especificidades, por hora, focadas na relevância do levantamento, resgate e valorização do patrimônio histórico-cultural como ordenador da paisagem; que possa contribuir para o desenvolvimento de propostas planejadas aos (re) desenhos urbanos de Marília e demais cidades da região da Alta Paulista, cujos pressupostos teóricos decorrem das pesquisas, a seguir referenciadas.

\section{PATRIMONIO CULTURAL: EM BUSCA DE DEFINIÇÃO}

Patrimônio Cultural compreende as obras artísticas "dos artistas, arquitetos, músicos, escritores e sábios, assim como as criações anônimas surgidas da alma popular e o conjunto de valores que dão sentido à vida"; além do conjunto de "obras materiais e não materiais", (...) que "expressam a criatividade desse povo: a língua, os ritos, as crenças, os lugares e monumentos históricos, a cultura, as obras de arte e os arquivos e bibliotecas" (ICOMOS, 1985: 4).

$\mathrm{Na}$ identificação do patrimônio histórico-cultural do lugar, vislumbra-se a importância dos saberes e as manifestações de diversos seus grupos sociais; seja, entre outros condicionantes, através da lógica do sistema capitalista, fundamental na definição do seu panorama físico-territorial e econômico, como dos fenômenos migratórios, recorrentes a partir da produção agrária ou industrial existente (Gaiotto, 2009).

E, aqui, vale ressaltar os estudos realizados por GAIOTTO (2002), onde a diversidade local, visivelmente, intensificou ocupações dos solos agricultáveis, transformando a vida nos pequenos núcleos urbanos, principalmente, a partir do inicio do XX.

Situação semelhante, também, deve ter acontecido na maioria das localidades do antigo traçado da Alta Paulista, na faixa das terras entre os rios do Peixe e Aguapeí, objeto desta proposta. Assim, na medida em que o presente manifestar as recorrências do passado, a história servirá ao planejamento. Afirmativa que, nesse primeiro momento, demonstra umas das preocupações centrais desta proposta, no apreender os sentidos de Patrimônio e Paisagem Cultural para as comunidades envolvidas, relacioná-las ao futuro das atividades planejadas de intervenções e novos desenhos urbanos. 
Para SANTOS (1997: 62), no "processo seletivo de informações" a interpretação da paisagem depende da percepção de cada individuo, variando assim a partir do repertório, sentidos e vivências de cada um.

Ainda na defesa de SANTOS (1994: 66), "a paisagem não se cria de uma só vez, mas por acréscimos, substituições (...). Uma paisagem é uma escrita sobre a outra, é um conjunto de objetos que têm idades diferentes, é uma herança de muitos diferentes momentos". E, tal dinâmica permite conceituar Patrimônio e Paisagem Cultural, em constante construção.

Por isso, ao identificar a Paisagem Cultural abarca-se as construções ou os conjuntos edificados do lugar, mas também os seus vazios enquanto elementos da memória e identidade de um povo, residente ou não, mas envolvido com tal ambiência. Dessa maneira, o binômio "Patrimônio Paisagem" possui caráter ainda mais amplo na identificação dos valores para o resgate da memória do lugar com vistas à preservação do bem maior, calcado nas mais simples manifestações culturais importantes na construção da identidade de uma comunidade (Gaiotto, 2009).

\section{OBJETIVOS DA PESQUISA}

\section{OBJETIVO GERAL}

Investigar os mais coerentes caminhos para a formulação de propostas pertinentes com a análise espacial urbano-rural e a percepção ambiental baseada nos aspectos simbólicos e comportamentais, ou seja, a interação das formas espaciais e os seus cidadãos: os aspectos relativos às atividades econômicas; o uso social e a sua relação com o ambiente natural e/ou construído; as pressões sociais, funcionais, econômicas, culturais e ambientais sobre as áreas ocupadas a partir de 1970, até os dias de hoje.

A percepção espacial derivada da história das ocupações humanas, vigentes nas localidades a serem estudadas, que sirva ao planejamento das mesmas, e também da região objeto desta proposta, entre os rios do Peixe e Aguapeí, até a foz de ambos, no rio Paraná. 


\section{OBJETIVOS ESPECIFICOS}

Repensar o conhecimento metodológico aplicado na realidade do futuro Arquiteto e Urbanista, que se apropria de determinações ao uso e ocupação dos solos, na busca de soluções e diretrizes para intervenções planejadas no espaço da cidade, e/ou do campo. Identificadas a partir dos elementos ordenadores do perfil do Patrimônio e Paisagem Cultural do lugar, aqui, representado pela porção noroeste paulista, principalmente pela cidade porte médio, Marília, que polariza outras, bem menores, tal abordagem visa:

i. Interpretar o papel do Patrimônio Cultural como ordenador dessa Paisagem, referenciado nos ciclos econômicos pelos quais passou essa região;

ii. Identificar e mapear os processos inerentes à implantação física desse Patrimônio, principalmente o edificado de interesse histórico-arquitetônico, se relacionados à co-evolução da Paisagem Cultural e importante aos (re) desenhos das cidades envolvidas;

iii. Propor uma metodologia participativa que valorize a "cultura caipira" e o resgate histórico dos assentamentos humanos;

iv. Identificar os efetivos instrumentos reguladores e fiscalizadores do urbano e rural, a partir de sua relação com a urbanização dispersa recorrente nas ultimas décadas, considerando a participação da comunidade na tomada de decisões quanto ao desenvolvimento local e regional; aos Planos Diretores, e às políticas municipais. Soluções aos novos desafios, tanto na produção de documentos e propostas, que aprofundarão as questões emergentes, como as de caráter sócio-econômicas e ambientais, de peculiar interesse dos municípios envolvidos, vislumbrando os pressupostos da Lei Federal n. $-10.257 / 01$, que aprovou o Estatuto da Cidade, no Brasil;

v. Viabilizar as políticas públicas de gestão territorial que supririam, entre outras, as demandas por emprego e renda;

vi. Elaborar intervenções planejadas e novos desenhos urbanos, principalmente para Marília;

vii. Contribuir para a formulação de um modelo de procedimentos de investigação e sustentação do planejamento e gestão do território também dentro das novas 
perspectivas oferecidas pela visão holística, que possam fomentar pesquisas e medidas mais sustentáveis à preservação do ambiente nessa região;

viii. Garantir a acessibilidade e mobilidade urbana;

ix. Subsidiar outros projetos de pesquisa, além das possíveis propostas planejadas, que considerem o desenvolvimento sócio-econômico, baseado no resgate e valorização, preservação e conservação do patrimônio cultural dessa região;

x. Ao considerar que a localização da faixa de terras, entre o rio do Peixe e Aguapeí, pode-se permitir o questionamento quanto aos seus limites físicos, que também envolvem as dinâmicas urbanas e rurais dessa região, bem como a divisão de bacias hidrográficas e suas sub-bacias, proposta pela Lei Estadual 7663/91. E, aqui, cabe destacar mais um objetivo desta proposta, ou seja, tentar comprovar se os limites físicos dessa região hidrográfica equivalem aos sócio-econômicos, culturais e ambientais, principalmente no bojo das variáveis que interferem nos seus (re) desenhos urbanos.

\section{DELIMITAÇÃO DA ÁREA EM ESTUDO}

A Lei $n . \cong 7663 / 91$ estabelece as Unidades de Gerenciamento dos Recursos Hídricos UGRHI - no Estado de São Paulo, cujos municípios foram agrupados de acordo com seus interesses comuns (São Paulo, 1991).

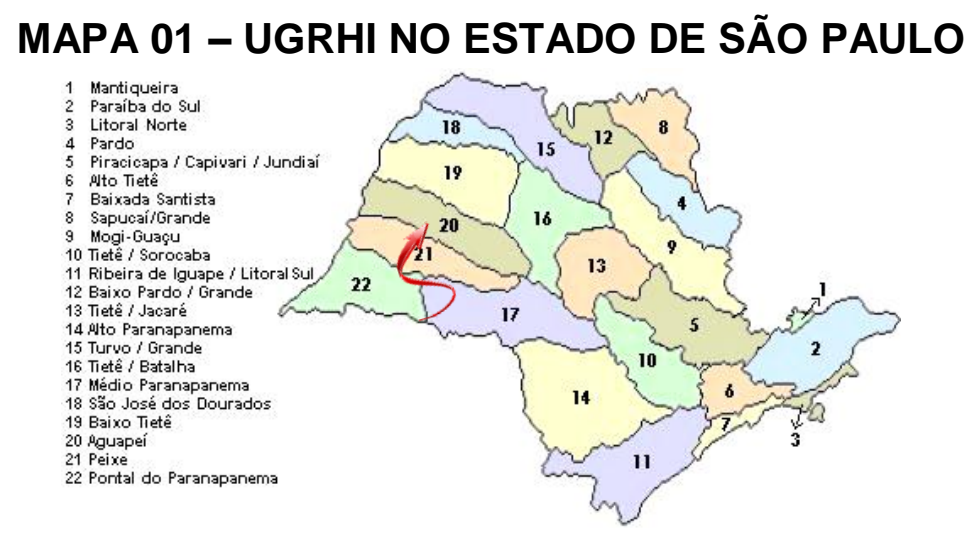

Fonte: CETESB, apud GAIOTTO, 2002: 04 
Para a finalidade desta pesquisa, interessa considerar a UGRH 20, cujo principal rio Aguapeí percorre uma faixa de terras, do município de Garça até o Rio Paraná, coincidente ao antigo traçado do Tronco Oeste da Companhia Paulista de Estradas de Ferro, conhecido como região da Alta Paulista, na sua maior parte, ocupada a partir da primeira metade do Século XX.

$\mathrm{E}$, aqui, vale destaque para a cidade de médio porte, Marilia, considerada a capital da Alta Paulista, com 225.938 habitantes (IBGE/2009: 76); além de outras, bem menores, como Tupã, Parapuã, Rinópolis, Osvaldo Cruz, Inúbia Paulista, Lucélia, Adamantina, Pacaembu, Dracena e Panorama (esta na margem do Rio Paraná); atualmente pertecentes a denominada Nova Alta Paulista, que também compreende outros municípios, tais como Arco-Íris, Bastos, Flora Rica, Flórida Paulista, Herculândia, lacri, Irapuru, Junqueirópolis, Mariápolis, Monte Castelo, Nova Guataporanga, Ouro Verde, Paulicéia, Pracinha, Queiroz, Sagres, Salmourão, Santa Mercedes, São João do Pau D' Alho e Tupi Paulista.

\section{NATUREZA DO PROBLEMA E JUSTIFICATIVAS DA PROPOSTA}

No decorrer do século $\mathrm{XX}$, do ponto de vista social da ocupação do território, no mundo todo, aconteceram "processos de crescimento e desenvolvimento econômico altamente segregadores" devido à demasiada "concentração do capital em determinadas áreas, geralmente urbanizadas, em detrimento de outras", mais periféricas, "onde o conteúdo da ruralidade", na sua maioria, se consolida na franja da miséria e da marginalidade humana. A partir da segunda metade do século $X X$, nos países em desenvolvimento, a exemplo do Brasil, o crescente processo de industrialização propicia a concentração de riqueza em áreas específicas e urbanizadas, que também marginalizam outras, constituindo os novos arranjos regionais e intra-regionais, âncoras dos novos modos de produção e consumo, determinantes sócio-econômicos, que permeiam a atualidade dos tempos e propiciam 
outras oportunidades de inserção sócio-produtiva, culturais e ambientais (Portuguez, apud Gaiotto 2006: 01).

As transformações mundiais e a consequente globalização favorecida pela revolução tecnicista e informacional, além da facilidade de comunicação instantânea, entre os diferentes povos; aos novos territórios, economicamente ascendentes, propiciam novos olhares (Santos et.al, apud Gaiotto, 2009).

A pós-modernidade enquanto marca cultural da sociedade globalizada, também, indica avanço em todas as áreas manifestadas por uma nação. Identificados na economia, nos avanços científicos e na cultura do povo, a máxima expansão da produção e do tecnicismo pauta-se na alegação de que todos teriam os mesmos direitos de consumir os bens e serviços gerados pelo capitalismo, ora, em ascensão (Gastal et. al, apud Gaiotto, 2009).

No Brasil, a partir da década de 1970, marco do desenvolvimento econômico e social em detrimento da qualidade de vida e do equilíbrio ambiental devido às transformações na distribuição espacial das atividades como um todo, sem o adequado planejamento; se intensifica a pressão sobre os recursos naturais, principalmente os hídricos. No interior paulista, não somente em função do uso dos venenos agrícolas, como da deficiência nos serviços básicos de infra-estrutura urbana, especialmente por deixar de atender à indústria em expansão, tem levado à variedade de situações alarmantes (Gaiotto, 2002 e 2006).

Por isso, esta proposta de pesquisa ancora-se no marco temporal, a partir de 1970, até os dias de hoje, nos quais as influências da pós-modernidade permitem incorporar, através das altas tecnológicas, os fenômenos culturais e sociais recorrentes que, nas suas especificidades, incentivam os deslocamentos e o multiculturalismo. No entanto, na organização desses estudos, há que se cuidar também dos prováveis efeitos negativos, que poderão acontecer ao (re) pensar e propor novos desenhos para as localidades, tais como da violência; do aumento da desigualdade social; do desemprego, entre outros, que se opõem aos pressupostos do desenvolvimento sustentável, principalmente onde se valoriza a atração do maior lucro econômico gerado versus a qualidade de vida da população envolvida. Desse modo, esta proposta justifica-se na medida em que traz a 
tona diferentes valores do contexto regional, tendo em vista a análise e interpretação da paisagem cultural para os (re) desenhos urbanos, na ordenação desse território.

Além do que, atualmente, se vivencia mais uma transição histórica, pautada nas pressões dos avanços tecnológicos e das exclusões sociais, influenciadas também pela mídia e pelo novo posicionamento empresarial, inclusive no setor do turismo (Costa, apud Gaiotto, 2009).

Situação visível também na área em estudo, onde se entende urgência de ações mais sustentáveis do ponto de vista sócio-cultural e responsabilidade sócio-ambiental, tanto para garantir o seu desenvolvimento, como para valorizar o seu patrimônio cultural, manifestado nos bens materiais, imateriais e ambientais. Assim, este projeto ainda pretende colaborar com a redução dos desequilíbrios territoriais e sociais, além de buscar eliminar as disparidades ambientais de acordo com o princípio da sustentabilidade ambiental, igualdade social e do crescimento da economia, diminuindo os impactos sócioculturais.

Semelhante ao constatado por GAIOTTO (2002); os municípios, que compõe a UGRHI 20 também devem lançar, senão toda, a maior parte dos seus resíduos diretamente nos principais rios e afluentes das regiões dos rios do Peixe e Aguapei. Além do que, a diversidade do setor industrial, ali, existente, mesmo que fiscalizada pelos órgãos e competências de governo, deve deixar a desejar no que se refere ao tratamento e disposição final dos seus efluentes, contribuindo sobremaneira para o incremento da poluição inorgânica, somada aos despejos irregulares do vinhoto, adubos e defensivos agrícolas, empregados na atualidade, também, da produção canavieira.

Por outro lado, os núcleos e assentamentos urbanizados, cuja dispersão também acontece no território rural, principalmente na forma de condomínios fechados de moradia e/ou de lazer para o médio e alto padrão de renda (Spósito, 2007), além daqueles, ao longo dos principais eixos rodoviários e mananciais de água, visivelmente colaboram para pressionar os recursos naturais, ali existentes.

Naturalmente, os empreendimentos ligados ao turismo, nas suas diversas modalidades, desde a prestação de serviços pessoais às chácaras de recreio ou mesmo as atividades ditas urbanas, atualmente instaladas nas áreas rurais ou nas franjas, denominadas rural- 
urbano, interferem na paisagem cultural e nos usos e ocupações das terras, tornando urgente a adequação de políticas aos gestores públicos municipais. (Santoro et. al, 2004). $\mathrm{E}$, quiçá, devido às necessidades dos recursos e atrativos básicos ao turismo, com vistas ao desenvolvimento de uma atividade de consumo mais sustentável; o poder público, em parceria com a iniciativa privada, universidades e a sociedade civil organizada, realmente possa pautar agendas para as proposições condicionantes aos ambientes melhor conservados e preservados, tanto do ponto de vista ambiental, como do patrimônio histórico-cultural, peculiar a cada localidade, sem esquecer as influências de âmbito regional, nacional ou internacional, conforme o caso.

A partir do binômio "Patrimônio e Paisagem Cultural", esta abordagem pretende o desenvolvimento de propostas mais sustentáveis, que, por hora, encontram-se alicerçadas em processos agroindustriais e agropecuários, entre outros modos de produção regional.

Por fim, entende-se que os pressupostos da sustentabilidade devem ser utilizados como fatores de abordagens exploratórias nas questões do planejamento; tanto que, nas intervenções e novos desenhos urbanos das cidades da região entre rios do Peixe e Aguapeí tais pressupostos podem colaborar com a redução dos desequilíbrios territoriais e sociais e das disparidades ambientais de acordo com o princípio de sustentabilidade ambiental, de igualdade e de crescimento da economia, minimizando os impactos sócioculturais para essa e gerações futuras.

Além disso, esta proposta pretende colaborar na valorização da "cultura caipira", dessa região; na preservação e conservação do seu binômio "patrimônio e paisagem cultural"; na geração de empregos e renda complementares as atividades rurais, ali, existentes, viabilizando a fixação do homem no campo, com incentivos ao êxodo cidade-campo; no planejamento dos (re) desenhos urbanos e rurais, ou seja, melhor definição e controle das atividades ligadas ao desenvolvimento sócio-econômico e cultural, (muitos, atuando na irregularidade e/ou clandestinidade), através de políticas públicas com gestão compartilhada (público-privado). 


\section{ABORDAGEM METODOLÓGICA E PRODEDIMENTOS DA PESQUISA}

No art. 40 (parágrafo 2.ํ) do Estatuto da Cidade claro está que nos Planos Diretores se considere o município como um todo, ou seja, deve-se priorizar a interação e a complementaridade entre as atividades urbanas e rurais, visando o desenvolvimento social e econômico do município e do território; respeitando a participação da comunidade com metodologia baseada no processo de planejamento participativo (Brasil, 2001).

Assim, para alcançar os objetivos desta proposta, bem como as proposituras dessa Lei nacional, há que se combinar aos estudos do passado o levantamento das condições atuais. $\mathrm{E}$ a abordagem retrospectiva dos ciclos econômicos pelos quais passou a região da bacia do Rio Aguapeí, mesmo captada em fontes secundárias, levará ao entendimento do contexto atual. Sendo que, as fontes consideradas secundárias se baseiam no levantamento histórico das localidades e região, como um todo, além dos clássicos da história brasileira, recomendados na continuidade da pesquisa.

Inicialmente, pretende-se levantar a atualidade e as principais realidades das comunidades urbanas e rurais, pertencentes à bacia do Rio Aguapeí, destacando-se Marília, aqui, considerada importante na rede de municípios, pois visivelmente polariza o desenvolvimento dessa região hidrográfica.

As breves considerações da memória e identidade de um povo visam entender como essa memória pode contribuir para o resgate e/ou preservação e conservação dos valores sócio-culturais estabelecidos pela comunidade envolvida.

O movimento das pessoas corresponde à etapa da produção que esta se dando naquele momento. Todos são produtores - o operário, o artista de teatro, 0 vendedor... etc., mesmo quem não esta diretamente no processo de produção, já que também consome. É a maneira com que se dá a produção, e o intercâmbio entre os homens que dá um aspecto à paisagem (Santos, apud Gaiotto, 2009: 15).

Por isso, tal estudo pretende diagnosticar (do ponto de vista das pessoas, de alguma maneira envolvidas no processo de ocupação desse território) o verdadeiro panorama dessas áreas, através de visitas técnicas e entrevistas com os representantes da população, das prefeituras e outros órgãos governamentais, e/ou da iniciativa privada. 
Patrimônio Cultural é o conjunto de bens, de natureza material e imaterial, que guarda em si referencias à identidade, a ação e a memória dos diferentes grupos sociais. É um elemento importante para o desenvolvimento sustentado, a promoção do bem estar social, a participação e a cidadania (Ghirardello et. al, 2008).

$\mathrm{Na}$ condição de ser no lugar, ou mesmo do lugar, importa saber de que forma esses retratos memorialísticos podem contribuir para o conhecimento da história de cada comunidade envolvida, e, ao mesmo tempo, sustentar a identidade e a qualidade de vida de seus moradores.

Num segundo momento, pretende-se o levantamento da Paisagem Cultural dessa região, através das visitas de campo a serem elaboradas conforme a necessidade, no contexto da localização do patrimônio histórico-cultural nos municípios afins enquanto subsídio das propostas planejadas para as futuras intervenções e desenhos urbanos mais sustentáveis, tanto em nível local, como regional.

O planejamento da produção e a gestão de serviços integrados em unidades regionais, definidas por micro-bacias hidrográficas, constituem o método de abordagem mais adequado a estudos transdisciplinares que enfoquem o ambiente construído no meio rural, pois abrange todas as possíveis correlações nos diversos âmbitos da arquitetura rural: planos de produção e comercialização agrícola e de serviços não agrícolas; manejo dos recursos naturais, principalmente os recursos hídricos e florestais; ordenação territorial, planejamento ambiental e agro-ecológico; e políticas de desenvolvimento rural sustentável, incorporando modelos de gestão local, educação, assistência técnica, pesquisa e extensão baseadas em conceitos de sustentabilidade e eco-eficiência (Argollo Ferrão, 2006: 04).

Considerar o objeto de estudo dessa proposta - a Bacia do Aguapeí, onde se insere Marília e seus limítrofes -, significa priorizar a análise dos processos influenciados pelo desenvolvimento do setor agroindustrial, que agrega e assegura a valorização econômica das funções baseadas na agricultura em si, e das atividades complementares, provenientes de rendimentos não agrícolas, ali, existentes.

Por isso, na identificação das paisagens culturais através de pesquisas de campo (entrevistas qualitativas de caráter exploratório) espera-se facilitar e legitimar o patrimônio cultural edificado dessa região, cujo levantamento envolverá, num primeiro momento, as atuais unidades produtivas e as cadeias de produção agroindustrial e/ou agropecuária, até o passado, representado pela "marcha do café" rumo a Alta Paulista. 
Nesse viés, destaca-se a necessidade de constituir a leitura social do território rural, suas particularidades e funções estabelecidas a partir de temas do planejamento, tais como distribuição da população; processos físico-naturais da paisagem; desenvolvimento econômico; saneamento ambiental e eficiência energética, entre outras (Santoro et. al, 2004).

Respaldados na atualidade, pretende-se aplicar os conceitos de planejamento participativo, considerando os aspectos sócio-econômicos, culturais e ambientais das localidades envolvidas, nesta proposição.

Ao planejamento municipal, regional e ambiental, pretendem-se realizar estudos que visem propostas aplicáveis as políticas públicas, baseadas em teorias consolidadas e legislações pertinentes ao devido uso e ocupação das terras dessa região, correspondente a bacia hidrográfica do Aguapeí. E, aqui, encerra-se na finalidade principal desta proposta, quanto ao desenvolvimento das comunidades urbanas e rurais sem impactos para o ambiente, principalmente na proteção e conservação dos mananciais de água, ali, existentes.

\section{CONSIDERAÇÕES FINAIS}

Outros pesquisadores serão bem vindos neste projeto, cujo objetivo, também, seria promover a integração e a cooperação, através da troca de experiências e de informações obtidas entre os diversos profissionais especialistas.

Além disso, em cada uma das etapas, cujas metas se alinhavam ao longo dessa descrição, para que o projeto se torne organizado e dirigido à finalização de um produto, que jamais pretende se tornar acabado em si mesmo. Igualmente passíveis de criticas construtivas, principalmente, às pesquisas futuras; este projeto enquanto produto final de uma proposta visa o "planejamento diferente, onde o bem histórico-cultural possa propiciar inclusão identitária e social de quem participa ativamente dessa dinâmica" (BORTONE, 2008: 6). 
Esses novos conceitos, que retratam novas visões de mundo, sejam elas regionais, nacionais ou continentais, só poderão lograr bons frutos se aliados ao ensino que, mais que nunca, tem chances de realizar uma de suas maiores potencialidades: desenvolver o pensamento reflexivo e inovador, sobretudo possibilitando novas abordagens às formas e vivências de velhos paradigmas. (Bortone, 2008: 7)

Em momento algum, faltaram os famosos questionamentos sobre a atualidade dos fatos, representados no respeito aos saberes e fazeres das populações envolvidas na pesquisa, cujo resgate e valorização do passado colaboram para interpretar o presente e, até, podem garantir prognósticos futuros. E, aqui, a história serve ao planejamento.

$\mathrm{Na}$ atualidade desta temática, ressaltam tais propostas lastradas na valorização, preservação e conservação do patrimônio cultural como ordenador da paisagem, que apresenta como carro chefe, o (re) desenho urbano de localidades, tal e qual Marília, a maior da região em estudo, visando o efetivo e mais sustentável planejamento dessa faixa de terras, entre rios do Peixe e Aguapeí.

A "liberdade" para o desenvolvimento desta proposta encontra-se na possibilidade de aplicação em qualquer região hidrográfica; por isso, pode servir como exemplo metodológico, pautado na pesquisa do binômio "Patrimônio e Paisagem cultural" como ordenador do território.

Por fim, enfatiza-se que esta proposta se encontra em construção e aberta ao diálogo e à possibilidade de inserção e/ou integração com outros pesquisadores, inclusive aqueles, pertencentes a outras áreas, correlatas e/ou transversais a este projeto de pesquisa. Assim, pretende-se manter os pressupostos iniciais deste relato, ou seja, a efetiva transdiciplinaridade nas pesquisas relacionadas à Arquitetura e Urbanismo.

\section{REFERÊNCIAS}

ARGOLLO FERRÃO, A. M. (2006) Arquitetura Rural e o Agro turismo, in Anais do XXXV Congresso Brasileiro de Engenharia Agrícola, João Pessoa, 31/07 a 04/08.

(2004) Arquitetura Rural dentro do contexto dos estudos sobre Patrimônio e Paisagens Culturais, Departamento de Urbanismo y Ordenación Territorial, ETSAB-UPC, Barcelona [Espanha], Relatório: Pesquisa de Pós Doutorado.

BRASIL (2001). Estatuto da Cidade - Lei Federal, Lei Federal, n. 10.257, Brasília/DF: Ministério das Cidades. 
BORTONE, M. E. (2008). Métodos de Pesquisa e Ensino. Brasília: CET, UNB, Apostila. CBH-AP (2009). CBH-AP, um breve histórico. Disponível em: http://www.comiteap.sp.gov.br/apresentacao/ - Acesso em 02 de Dezembro/2009.

GHIRARDELLO, N.; Faria, G. G. M.; Spisso, B.; Shopia, P. E. M.; Ignatios, R. P. V.; Hahecki, H. S. (2008). Patrimônio Histórico: como e por que preservar. 1. ed. Bauru: Canal 6 / Imprensa Oficial do Estado de São Paulo, v. 7000. 34 p.

GAIOTTO, M. a. (2009). Patrimônio e Paisagem cultural: contribuição ao retrato memorialístico para o desenvolvimento do Turismo no Município de Cerquilho/SP. Monografia, final de Curso de Especialização "Formação de Professores em Turismo", Brasília/DF: Centro de Estudos de Turismo, Universidade de Brasília.

. (2006) Diagnóstico dos Impactos Sócio-Econômicos e Ambientais visando o Planejamento Territorial: uma proposta para a urbanização dispersa no Eixo da Rodovia Castelo Branco, na região do Baixo Rio Sorocaba e Médio Tietê-SP/Brasil, in Anais do XII Congresso Ibero-americano de Urbanismo, Salamanca [Espanha], 1618/10, 2006.

(2004) Aspectos sócio-ambientais dos resíduos na Bacia do Rio Sorocaba-SP: uma contribuição ao desenvolvimento regional do turismo ecológico, in Anais do Congresso de Ciência e Tecnologia em Resíduos e Desenvolvimento Sustentável (ICTR'2004), Florianópolis-SC: NISAM/USP, 17-20/10 de 2004.

(2002) Água Viva: Contribuição ao diagnóstico das tendências Ambientais atuais e ao Planejamento da preservação dos Recursos Hídricos da Sub-Bacia do Baixo Rio Sorocaba, Tese de Doutorado, São Paulo/SP: FAU-USP.

IBGE. (2009). Estimativas da população para 1ํ de julho de 2009. Disponível em: http://www.ibge.gov.br/home/estatistica/populacao/estimativa2009/POP2009_DOU.pdf Acesso em 03/Dez. de 2009.

ICOMOS. (1985) Declaração do México, in Conferência Mundial sobre as Políticas Culturais. Disponível em:

http://portal.iphan.gov.br/portal/baixaFcdAnexo.do;jsessionid=C5F366D465A5C872BF50D 0723DC23DC5?id=255 - Portal do IPHAN - Acesso em 18/01/2008.

LANDIM, P. da C. (2004). Desenho de paisagem urbana, São Paulo: Editora UNESP. MORIN, E. (2003) Introdução ao pensamento complexo, 4. ed., Instituto Piaget, Portugal.

SANTORO, P. e Pinheiro, E. (org.) (2004) O Município e as Áreas Rurais. São Paulo: Instituto Polis.

SANTOS, M. A natureza do espaço: técnica e tempo. Razão e emoção. São Paulo: Hucitec, 1997.

Metamorfose do Espaço Habitado. São Paulo: Hucitec, 1994.

SÃO PAULO (1991). Lei n. 7663 estabelece vinte e duas Unidades de Gerenciamento de Recursos Hídricos (UGRHI), no Estado de São Paulo. 


\section{Periódica Eletrânica

SPOSITO, M. E. B. (2007), Reestruturação Urbana e Segregação Socioespacial no Interior Paulista. in Revista Electrónica de Geografía y Ciências Sociales, Barcelona: Universidad de Barcelona, [Nueva serie de GeoCrítica. Cuadernos Críticos de Geografía Humana], Vol. XI, n. 245 (11), IX Colóquio de Geocritica, 1․ de Agosto/2007. Disponível em: http://www.ub.es/geocrit/sn/sn-24511.htm\#_edn1 - Acesso em 02 de Dezembro/2009. 